\title{
Logical network of genotoxic stress-induced NF- $\kappa B$ signal transduction predicts putative target structures for therapeutic intervention strategies
}

This article was published in the following Dove Press journal:

Advances and Applications in Bioinformatics and Chemistry

2 December 2009

Number of times this article has been viewed

\author{
Rainer Poltz' \\ Raimo Franke ${ }^{1, \#}$ \\ Katrin Schweitzer ${ }^{1}$ \\ Steffen Klamt ${ }^{2}$ \\ Ernst-Dieter Gilles ${ }^{2}$ \\ Michael Naumann' \\ 'Institute of Experimental Internal \\ Medicine, Otto von Guericke \\ University, Magdeburg, Germany; \\ ${ }^{2}$ Max Planck Institute for Dynamics \\ of Complex Technical Systems, \\ Magdeburg, Germany; \#Present \\ address: Department of Chemical \\ Biology, Helmholtz Centre for \\ Infection Research, Braunschweig, \\ Germany
}

\begin{abstract}
Genotoxic stress is induced by a broad range of DNA-damaging agents and could lead to a variety of human diseases including cancer. DNA damage is also therapeutically induced for cancer treatment with the aim to eliminate tumor cells. However, the effectiveness of radio- and chemotherapy is strongly hampered by tumor cell resistance. A major reason for radio- and chemotherapeutic resistances is the simultaneous activation of cell survival pathways resulting in the activation of the transcription factor nuclear factor-kappa $\mathrm{B}(\mathrm{NF}-\mathrm{\kappa} \mathrm{B})$. Here, we present a Boolean network model of the NF- $\kappa B$ signal transduction induced by genotoxic stress in epithelial cells. For the representation and analysis of the model, we used the formalism of logical interaction hypergraphs. Model reconstruction was based on a careful meta-analysis of published data. By calculating minimal intervention sets, we identified p53-induced protein with a death domain (PIDD), receptor-interacting protein 1 (RIP1), and protein inhibitor of activated STAT y (PIASy) as putative therapeutic targets to abrogate NF- $\kappa \mathrm{B}$ activation resulting in apoptosis. Targeting these structures therapeutically may potentiate the effectiveness of radio- and chemotherapy. Thus, the presented model allows a better understanding of the signal transduction in tumor cells and provides candidates as new therapeutic target structures.
\end{abstract}

Keywords: apoptosis, Boolean network, cancer therapy, DNA-damage response, NF-кB

\section{Background}

A highly relevant topic in biomedicine concerns the conditions of genotoxic stress that damages the genetic integrity of human cells. Genotoxic stress is induced by environmental agents such as ionizing radiation, ultraviolet (UV) light, ${ }^{1}$ or chemical pollutants (eg, cigarette smoke). ${ }^{2}$ Genotoxic stress triggers the activation of a complex network of signal transduction pathways collectively referred to as the DNA damage response. ${ }^{3}$ The pathways are driven by 'sensor' proteins that sense the DNA damage, and transmit the signals via 'transducer' proteins to a multitude of 'effector' proteins, which induce a cellular response including mechanisms to slow down or block cell proliferation at so-called cell-cycle checkpoints, ${ }^{4}$ followed by DNA repair, senescence, ${ }^{5}$ or elimination of damaged, hazardous cells by engaging apoptosis to avoid transformation into tumor cells. ${ }^{6}$

DNA double-strand breaks (DSBs) are among the most lethal types of DNA damage, and can be induced by ionizing radiation or topoisomerase inhibitors, both of which are commonly used in cancer treatment with the aim to eliminate tumor cells by apoptosis. The Mre11/Rad50/Nbs1 (MRN) sensor protein complex is among the first to be recruited to such lesions, mediating the autophosphorylation of ataxia telangiectasia
Correspondence: Michael Naumann Institute of Experimental Internal Medicine, Medical Faculty, Leipziger Str. 44, 39120 Magdeburg, Germany

$\mathrm{Tel}+4939 \mathrm{l}$ 67। 3227

Fax +49 391 67I 3312

Email naumann@med.ovgu.de 
mutated (ATM). ${ }^{7}$ ATM can phosphorylate checkpoint kinase 2 (Chk2), p53, and breast cancer type 1 susceptibility protein (BRCA1), which are involved in mediating cell cycle arrest and DNA repair or apoptosis. ${ }^{4}$ Moreover, DSBs can also cause a posttranslationally processed form of PIDD to enter the nucleus. ${ }^{89}$ Nuclear p53-induced protein with a death domain (PIDD) binds via receptor-interacting protein 1 (RIP1) to nuclear factor-kappa B (NF-KB) essential modulator (NEMO), ${ }^{10}$ which then becomes sumoylated by protein inhibitor of activated STAT y (PIASy). ${ }^{10,11}$ Thereafter, ATM phosphorylates NEMO, followed by its monoubquitinylation and export to the cytosol. ${ }^{11-14}$ Inside the cytosol, NEMO activates IKB kinase $\beta(\operatorname{IKK} \beta)^{11,12}$ to phosphorylate inhibitors of $\kappa \mathrm{Bs}$ (I $\mathrm{KBs}$ ), followed by their ubiquitinylation-mediated degradation. ${ }^{15}$ Since NF-KB dimers are retained in the cytosol by binding to IKBs, degradation of the latter leads to release of NF- $\mathrm{KB}$, enabling its entry into the nucleus to drive the transcription of dedicated target genes. ${ }^{16,17} \mathrm{NF}-\mathrm{\kappa B}$-regulated target genes mostly exert antiapoptotic effects. Therefore, a major reason for resistance of tumor cells against radio- and chemotherapy can be attributed to the activation of NF- $\mathrm{\kappa B}$ impeding the efficient elimination of cancer cells. ${ }^{18}$ Increase of the nuclear level of NF- $\mathrm{KB}$ has been observed in several human solid tumor cell lines and some breast tumors. ${ }^{18}$ This is one of the reasons why the molecular mechanisms of genotoxic stress response, in particular, the NF- $\kappa B-$ related pathways are of high interest.

Despite the high clinical relevance of the genotoxic stress response, the molecular interplay is poorly understood, particularly due to the high complexity of related signaling pathways, leading to the complication for finding promising drug targets for therapeutic treatments. Therefore, systems biological approaches might be of high value to give new insights into the understanding of the complex cellular networks. The prevailing formalism to model cellular networks is kinetic analysis, which has been mainly applied to signaling networks of smaller size. Qualitative (ie, parameterfree) models enable the computational representation and analysis of even large-scale signaling networks. A functional analysis of the network structure already enables researchers to address important issues, such as detection of networkwide functional interdependencies, identification of intervention strategies and predictions on the effects of perturbations. Boolean networks have been shown to be a useful tool for qualitative modeling of biological processes, particularly due to their computational simplicity. ${ }^{19-22}$ Recently, a particular representation of logical networks, logical interaction hypergraphs has been shown to be well suitable for visualization and qualitative analyses of logical models of signal transduction networks. ${ }^{23-25}$ Using this in silico approach, putative therapeutic targets in human signal transduction pathways induced by the pathogen Helicobacter pylori have been identified. ${ }^{26}$

Here, we present a logical model of the DNA-damage response in human epithelial cells with the major focus on the induction of the NF- $\mathrm{KB}$ system by DNA doublestrand breaks. By simulating treatment of tumor cells with ionizing radiation and the topoisomerase II inhibitor VP16 (VePesid ${ }^{\circledR}$, etoposide), we identified putative target molecules to impede tumor cell survival by abrogating activation of $\mathrm{NF}-\kappa \mathrm{B}$ while leaving apoptotic pathways unaffected. Further, our results give new insights into the understanding of complex signaling pathways, in particular the role of NF- $\kappa B$ in response to genotoxic stress.

\section{Methods}

\section{Data mining}

For the Boolean network assembly we screened the relevant literature through PubMed and accessed further data on signaling pathways via curate protein-protein interaction databases. ${ }^{27,28}$ Large amounts of published experimental works were evaluated and only high quality data from experiments using human epithelial cells were used for modeling. Information on intracellular localization of proteins were retrieved from the LOCATE database ${ }^{29}$ if this has not been indicated in the analyzed publications.

\section{Logical model construction and analysis}

For construction, visualization, and structural analyses of the signal transduction network, we employed the logical modeling framework of logical interaction hypergraphs. ${ }^{23-26}$ Logical interaction hypergraphs are based on a special representation of Boolean functions, known as 'sum of products', which requires only AND, OR, and NOT operators for describing the logical relationships. In a logical network, nodes typically correspond to variables that can attain only discrete values; in the simplest (Boolean) case, each species can only be 'on' (ie, 'active' or 'present') or 'off' (ie, 'inactive' or 'absent'). Hence, each node is considered as a binary variable. A Boolean function is assigned to each node, determining under which conditions it is 'on' or 'off'. Interaction graphs are only capable of representing dependencies between two species. Therefore, in interaction graphs, every relationship is represented by an arc, connecting one tail (start) node with one head (end) node. A species may be activated by several distinct signaling events independently. 
This is represented by a logical OR connection of all arcs sharing the same head node. Therefore, each arc represents one means by which the species represented by the head node becomes active. However, in signaling networks, an interaction often represents a relationship between more than two species. For example, DSBs arise (are 'on') if both camptothecin and a topoisomerase I are present (ie, both are 'on'). This logical AND connection is represented by a hyperarc: the two tail nodes reflect the premise, that both of them have to be 'on' in order to activate the head note. Generally, a hyperarc can have an arbitrary number of start and end nodes, ie, can have arbitrary cardinality. Again, any hyperarcs pointing into the same node are connected by a logical OR. Moreover, inhibiting influences are represented by a logical 'NOT'.

The network diagram was constructed using the software CellDesigner 4.0.1 (The Systems Biology Institute, Tokyo, Japan). ${ }^{30}$ We analyzed the logical model with the software CellNetAnalyzer 9.0 (CNA), a MATLAB package for graphtheoretical and logical analyses (The MathWorks, Natick, MA, USA). ${ }^{24}$

We studied the qualitative effects of input stimuli on downstream signaling events and on the logical pattern of outputs by computing logical steady states (LSS) of the network. ${ }^{23}$ Importantly, the calculation of LSS also provides the basis for calculations of minimal intervention sets, ${ }^{23,24}$ which are defined as minimal sets of network elements that are to be removed (by knockout, knockdown or inhibition) or to be added (by activation) to achieve a certain intervention goal. CNA enables the setting of a maximum cardinality (maximum number of interventions allowed) for each minimal intervention set calculation.

Some functions of $C N A$ operate on the level of the interaction graph underlying the logical model. The projection of a logical model to its underlying interaction graph can be conducted easily if a logical network is given in logical interaction hypergraph representation as in CNA (all the AND connections (hyperarcs) are being split into arcs). Within the interaction graph model one may then calculate graph-theoretical properties of the network including signaling paths, or the dependency matrix..$^{23,24}$ The latter reveals functional interdependencies between each pair of species, eg, revealing whether a species $i$ is an activator (ie, there are only positive paths) or an inhibitor (ie, there are only negative paths) or an ambivalent factor (ie, positive and negative paths to the selected species exist) for another species $j$. This feature facilitates qualitative predictions of the effects of perturbations or knockout experiments.

\section{Results and discussion \\ Boolean network of genotoxic stress-induced signal transduction}

Based on quality-controlled published data gained from experiments using human epithelial cell lines, we built a Boolean network of NF- $\kappa \mathrm{B}$ signal transduction in response to genotoxic stress (Figure 1). The network was drawn according to the recently released Systems Biology Graphical Notation process diagram level $1,{ }^{31}$ which facilitates the communication of knowledge about signal transduction networks.

The model encompasses 69 species connected by 72 reactions and reflects the typical structure of signaling networks. Therein, genotoxic stimuli constitute the input layer (top of the network). The signals will be transmitted to the intermediate layer, and processed. Eventually, the processed signals are connected to proteins in the output layer (bottom), eg, resulting in apoptosis, as indicated by dashed lines. The numbers assigned to the interactions in Figure 1 correspond to the numbers of the model reactions (equations) listed in Table 1. All model species are listed in Table 2. The proteins linked to apoptosis or cell survival are indicated in Table 3.

\section{Network-wide interdependencies revealed by the logical model}

For the analysis of the model, we calculated network-wide interdependencies comprehensively displayed in the dependency matrix (Figure 2). This matrix indicates the type of the impact of a certain species (left) on another species (bottom), regardless of the type of stimulus. For instance, it can be inferred from Figure 2, that ataxia telangiectasia and Rad3-related (ATR), which forms a complex with ATR interacting protein (ATRIP), has an inhibitory effect on Bcl-3/p52/p52. ATR activates p53 by phosphorylating it at serine 15 (equation 49, Table 1). ${ }^{32}$ Additionally, ATR phosphorylates checkpoint kinase 2 (Chk2) (equation 60), ${ }^{33,34}$ which subsequently initiates the degradation of murine double minute X (MDMX) (equation 66). ${ }^{35}$ Notably, MDMX itself ubiquitinylates $\mathrm{p} 53$, leading to degradation of $\mathrm{p} 53 .{ }^{35}$ Thus, ATR-mediated degradation of MDMX stabilizes p53, which in turn initiates degradation of Bcl-3 (equation 40). ${ }^{36}$ This represents an inhibition in a logical sense, whereby the formation of the Bcl-3/p52/p52 complex (equation 41) is impeded, which leads to the inactivation of the NF- $\mathrm{KB}$ complex p52/p52 36 and further induces apoptosis. Moreover, the MDMX molecule itself can be ubiquitinylated by the E3 ligase murine double minute 2 (MDM2), leading 

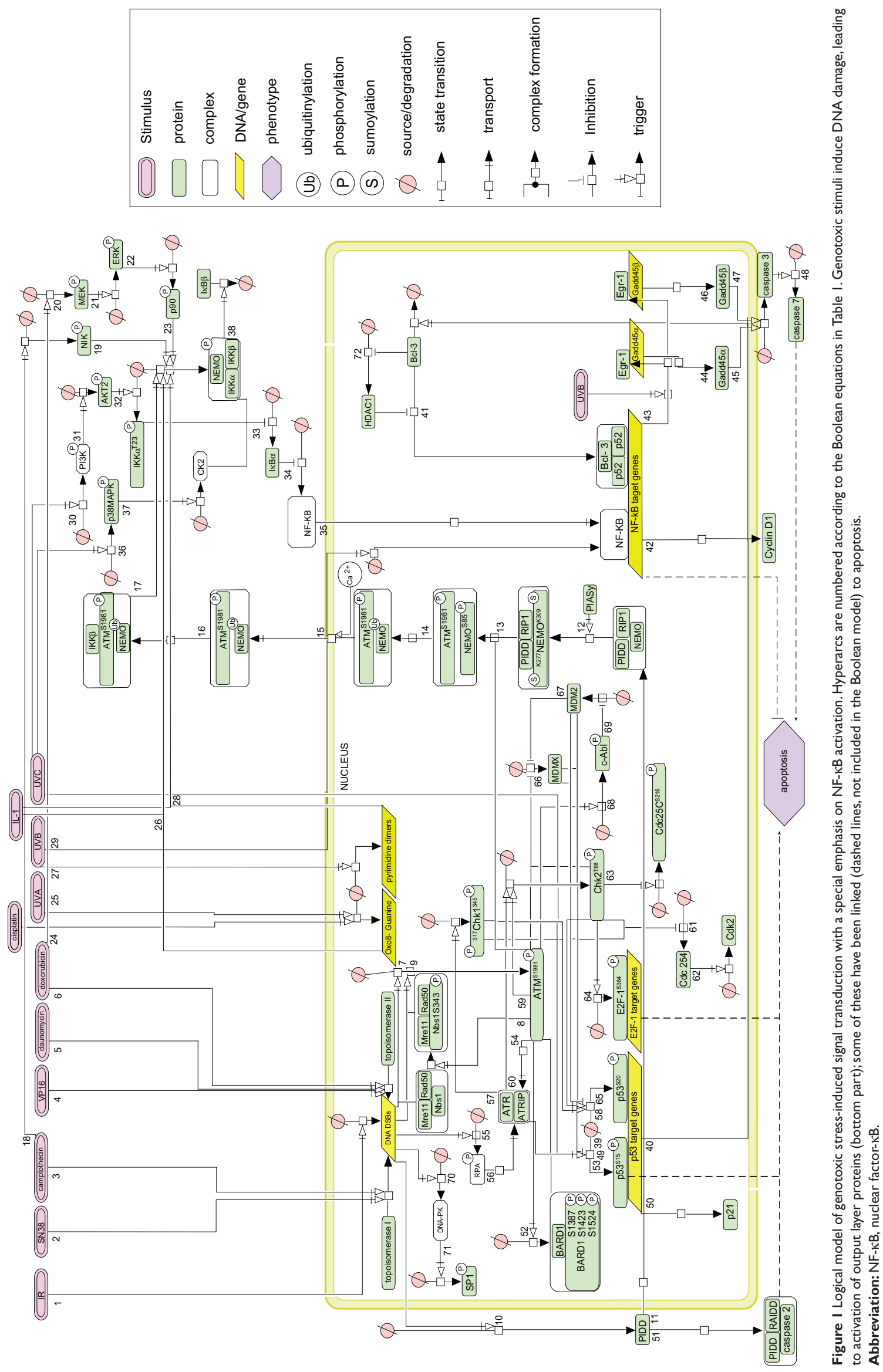
Table I The Boolean model reactions. Interactions of the logical model

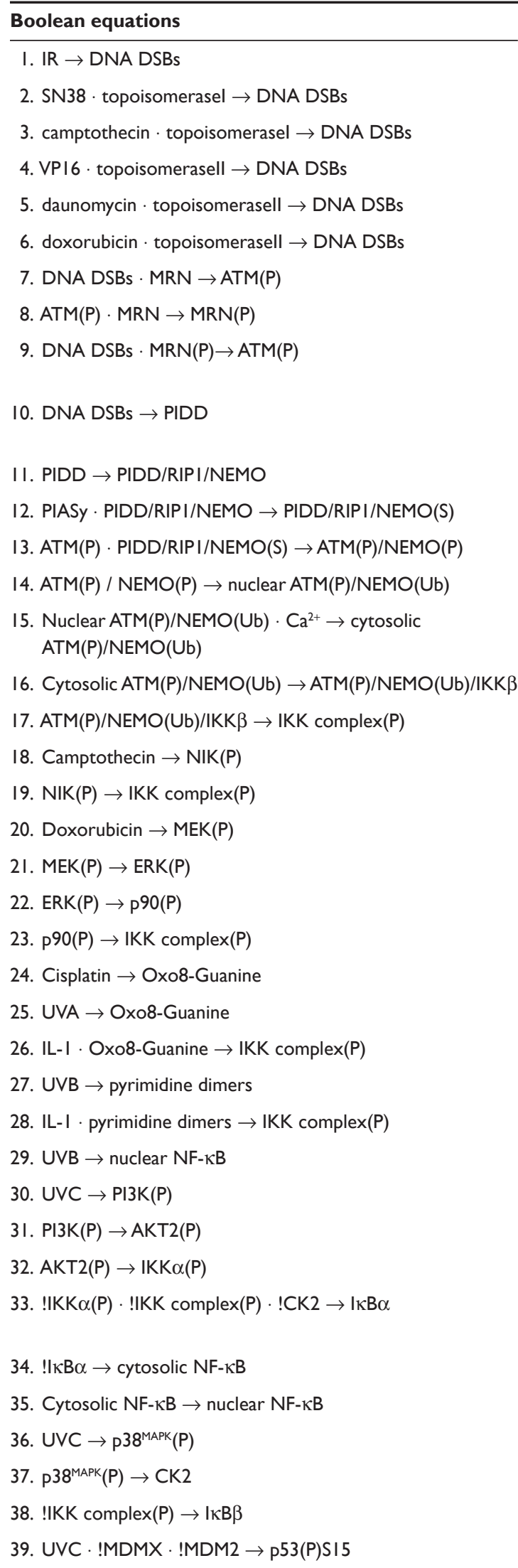

Explanations and references

lonizing radiation causes DNA double-strand breaks in all cell types ${ }^{51}$

SN 38 causes DNA double-strand breaks by inhibiting topoisomerase $I^{52}$

Camptothecin causes DNA double-strand breaks by inhibiting topoisomerase $\mathrm{I}^{52}$

VPI6 causes DNA double-strand breaks by inhibiting topoisomerase $\|^{53}$

Daunomycin causes DNA double-strand breaks by inhibiting topoisomerase $1 \mathrm{I}^{54}$

Doxorubicin causes DNA double-strand breaks by inhibiting topoisomerase ${ }^{155}$

The MRN complex facilitates autophosphorylation of ATM at serine $198 \mathbf{I}^{39,56,57}$

Activated ATM phosphorylates serine 343 of $\mathrm{Nbs}$ I within the MRN complex ${ }^{58}$

The phosphorylated MRN complex facilitates autophosphorylation of ATM at serine $|98|^{39,56,57}$

DNA double-strand breaks activate PIDD (by autocatalytic cleavage, potentially expression) $)^{8,9}$

Activated PIDD enters the nucleus and forms a complex with RIPI and NEMO ${ }^{10,9}$

PIASy sumoylates NEMO within the PIDD/RIPI/NEMO complex ${ }^{10,11}$

Upon sumoylation, ATM phosphorylates NEMO at serine $85^{12,13}$

Upon phosphorylation, NEMO becomes monoubiquitinylated ${ }^{12,13}$

Export of $A T M(P) / N E M O(U b)$ to the cytoplasm is dependent on $\mathrm{Ca}^{2+12,14}$

$\operatorname{ATM}(\mathrm{P}) / \mathrm{NEMO}(\mathrm{Ub})$ binds to IKK $\beta$ (or the whole IKK complex?) (1, I2 $^{12}$

IKK becomes activated by DNA double-strand breaks ${ }^{14,59}$

Camptothecin activates NF- $\kappa B$ partly via $\mathrm{NIK}^{60}$

NIK activates IKK $^{60}$

Doxorubicin activates MEK $^{61}$

MEK activates ERKI/261

ERKI/2 mediates binding of $p 90^{\text {rsk }}$ to IKK $\beta$, leading to phosphorylation of both ${ }^{61}$ ERKI/2 mediates binding of $p 90^{\text {rsk }}$ to IKK $\beta$, leading to phosphorylation of both ${ }^{61}$ Cisplatin leads to formation of Oxo8-Guanine lesions ${ }^{62}$

UVA leads to formation of Oxo8-Guanine lesions ${ }^{62}$

IL-I and Oxo8-Guanine synergistically activate IKK to phosphorylate I $\mathrm{B} \alpha^{62}$ UVB leads to formation of pyrimidine dimer lesions ${ }^{62}$

IL-I and pyrimidine dimers synergistically activate IKK to phosphorylate $I \kappa B \alpha^{62}$ UVB induces binding of NF- $\kappa B$ to $D N A^{63,64}$

UVC triggers activation of $\mathrm{PI} 3 \mathrm{~K}^{65}$

Activated PI3K mediates phosphorylation of AKT2 ${ }^{65}$

Phosphorylated AKT2 phosphorylates IKK $\alpha$ at threonine $23^{65}$

Several forms of genotoxic stress trigger IKK or CK2 to phosphorylate $I \kappa B \alpha$, leading to its proteolysis ${ }^{59,60,62,65-71}$

Degradation of $I \kappa B \alpha$ releases $N F-\kappa B^{15}$

Released NF- $\kappa B$ enters the nucleus ${ }^{15}$

UVC activates P38MAPK 70

Activated $\mathrm{p} 38^{\mathrm{MAPK}}$ activates $\mathrm{CK} 2^{70}$

Genotoxic stress-triggered phosphorylation of IKK mediates proteolysis of $1 \kappa B \beta^{60}$

UVC triggers phosphorylation of $\mathrm{p} 53$ at serine I5, MDM2 and MDMX ubiquitinylate $p 53$, leading to its proteolysis ${ }^{35,36,38,72}$

(Continued) 
Table I (Continued)

\begin{tabular}{|c|c|}
\hline Boolean equations & Explanations and references \\
\hline 40. !p53(P)SI5 $\rightarrow$ Bcl-3 & p53(P)SI5 destabilizes $\mathrm{Bcl}-3^{36}$ \\
\hline 4I. $\mathrm{Bcl}-3 \cdot$ ! HDACl $\rightarrow \mathrm{Bcl}-3 / \mathrm{p} 52 / \mathrm{p} 52$ & $\mathrm{Bcl}-3$ competes with $\mathrm{HDACl}$ for binding to the NF- $\kappa \mathrm{B} p 52 / \mathrm{p}^{2} 2^{36}$ \\
\hline 42. Bcl-3/p52/p52 $\rightarrow$ Cyclin DI & $\mathrm{Bcl}-3 / \mathrm{p} 52 / \mathrm{p} 52$ binds to DNA and drives the expression of Cyclin $\mathrm{DI}^{36}$ \\
\hline 43. UVB · nuclear NF-אB $\rightarrow$ Egr-I & UVB activates NF- $K B$ to drive the expression of Egr-I in several cell lines ${ }^{63,73,74}$ \\
\hline 44. Egr-I $\rightarrow$ Gadd $45 \alpha$ & Egr-I drives the expression of Gadd $45 \alpha$ in several cell lines ${ }^{63}$ \\
\hline 45. Gadd $45 \alpha \rightarrow$ caspase 3 & Gadd $45 \alpha$ activates caspase- $3^{63}$ \\
\hline 46. Egr-I $\rightarrow$ Gadd $45 \beta$ & Egr-I drives the expression of Gadd $45 \beta$ in several cell lines ${ }^{63}$ \\
\hline 47. Gadd $45 \beta \rightarrow$ caspase 3 & Gadd $45 \beta$ activates caspase- $3^{63}$ \\
\hline 48. caspase $3 \rightarrow$ caspase 7 & caspase- 3 becomes activated along with caspase- $7^{63}$ \\
\hline 49. ATR/ATRIP $\cdot$ !MDMX $\cdot$ !MDM2 $\rightarrow$ p53(P)SI5 & $\begin{array}{l}\text { ATR (which is bound to ATRIP) phosphorylates p53 at serine } 15^{32,75} \text {, MDM2 and } \\
\text { MDMX destabilize p53 (reaction 39). }\end{array}$ \\
\hline 50. $\mathrm{p} 53(\mathrm{P}) \mathrm{SI} 5 \rightarrow \mathrm{p} 2 \mathrm{I}$ & $\mathrm{p} 53(\mathrm{P}) \mathrm{S} 15$ drives the expression of $\mathrm{p} 2 \mathrm{I}^{76-78}$ \\
\hline 5I. PIDD $\rightarrow$ PIDD/RAIDD/caspase2 & Activated PIDD binds via RAIDD to caspase-2, which becomes activated. ${ }^{8,10,46}$ \\
\hline 52. ATM(P) $\rightarrow$ BARDI/BRCAI (P) & $\begin{array}{l}\text { Activated ATM phosphorylates serines I387, I } 423 \text { and I524 of BRCAI, which } \\
\text { requires binding to BARDI for stability } 40,79,80\end{array}$ \\
\hline $\begin{array}{l}\text { 53. ATM(P) } \cdot \text { !MDMX } \cdot \text { !MDM2 } \cdot \text { BARDI/BRCAI }(\mathrm{P}) \rightarrow \\
\text { p53(P)SI5 }\end{array}$ & $\begin{array}{l}\text { Activated ATM phosphoryltes } \mathrm{p} 53 \text { at serine } 15 \text {, dependent on phosphorylated } \\
\text { BRCA I. }{ }^{39,40,41} \text { MDM2 and MDMX destabilize } p 53 \text { (reaction 39). }\end{array}$ \\
\hline 54. ATM(P) $\rightarrow$ ATR/ATRIP & $\begin{array}{l}\text { Activated ATM recruits ATR/ATRIP to nuclear foci, potentially via the MRN } \\
\text { complex }\end{array}$ \\
\hline 55. DNA DSBs $\rightarrow$ RPA(P) & $\begin{array}{l}\text { DNA double-strand breaks are associated with single strand breaks, to where } \\
\text { RPA is recruited to within nuclear foci; it is unclear whether RPA is indeed } \\
\text { required for MRN complex assembly }{ }^{57,81}\end{array}$ \\
\hline 56. $\mathrm{RPA}(\mathrm{P}) \rightarrow$ ATR/ATRIP & Activated RPA recruits ATR/ATRIP to DNA ${ }^{75}$ \\
\hline 57. ATR/ATRIP $\rightarrow$ Chkl (P) & Activated ATR phosphorylates Chkl at serines 317 and $345^{81,82}$ \\
\hline 58. Chkl(P) $\cdot$ !MDMX $\cdot$ !MDM2 $\rightarrow$ p53(P)S20 & $\begin{array}{l}\text { Activated ChkI phosphorylates } p 53 \text { at serine } 20{ }^{79,83} \text { MDM2 and MDMX destabilize } \\
\text { p53 (reaction 39). }\end{array}$ \\
\hline 59. $\operatorname{ATM}(\mathrm{P}) \rightarrow \operatorname{Chk2}(\mathrm{P})$ & Activated ATM phosphorylates Chk2 at threonine $68^{84}$ \\
\hline 60. ATR/ATRIP $\rightarrow$ Chk2(P) & Activated ATR phosphorylates Chk2 at threonine $68 .^{33,34}$ \\
\hline 6I. !ChkI (P) $\cdot$ !Chk2(P) $\rightarrow$ Cdc25A & $\begin{array}{l}\text { ChkI and Chk2 phosphorylate Cdc25A at serines } 76 \text { and I23, respectively, leading } \\
\text { to its ubiquitinylation-mediated degradation }{ }^{85,86}\end{array}$ \\
\hline 62. $\mathrm{Cdc} 25 \mathrm{~A} \rightarrow \mathrm{Cdk} 2$ & Cdc25A activates Cdk2 by dephosphorylating it at tyrosine residues ${ }^{87}$ \\
\hline 63. Chk2(P) $\rightarrow$ Cdc25C(P) & Activated Chk2 phosphorylates Cdc25C at serine $216^{88}$ \\
\hline 64. Chk2(P) $\rightarrow$ E2F-I $(P)$ & Activated Chk2 stabilizes E2F-I by phosphorylation at serine $364^{89}$ \\
\hline 65. Chk2(P) $\cdot$ !MDMX $\cdot$ !MDM2 $\rightarrow$ p53(P)S20 & $\begin{array}{l}\text { Activated Chk2 mediates phosphorylation of } \mathrm{p} 53 \text { at serine } 20,{ }^{90} \text { MDM2 and } \\
\text { MDMX destabilize p53 (reaction 39). }\end{array}$ \\
\hline 66. !ATM(P) $\cdot$ !Chk2(P) $\rightarrow$ MDMX & $\begin{array}{l}\text { MDMX becomes phosphorylated by Chk } 2 \text { at serines } 342 \text { and } 367 \text { and by } \\
\text { activated ATM at serine } 403 \text {, leading to ubiquitinylation-mediated degradation } \\
\text { of MDMX } X^{35,37,43}\end{array}$ \\
\hline 67. !MDM2 $\cdot$ !c-Abl(P) $\rightarrow$ MDMX & $\begin{array}{l}\text { The E3 ligase MDM2 polyubiquitinylates MDMX, leading to its degradation, }{ }^{35,37,43} \\
\text { this works only as long as c-Abl itself is not destabilized (see reactions } 68,69 \text { ). }\end{array}$ \\
\hline 68. $\operatorname{ATM}(\mathrm{P}) \rightarrow \mathrm{c}-\mathrm{Abl}(\mathrm{P})$ & Activated ATM phosphorylates c-Abl. ${ }^{91,92}$ \\
\hline 69. !c-Abl(P) $\rightarrow$ MDM2 & $\begin{array}{l}\text { Activated c-Abl mediates phosphorylation of MDM2 at serine 397, leading to its } \\
\text { ubiquitinylation-mediated proteolysis }{ }^{38}\end{array}$ \\
\hline 70. DNA DSBs $\rightarrow$ DNA-PK & DNA double-strand breaks lead to DNA-PK-dependent phosphorylation of $\mathrm{Sp} \mathrm{I}^{93}$ \\
\hline 7I. DNA-PK $\rightarrow$ SpI(P) & DNA double-strand breaks lead to DNA-PK-dependent phosphorylation of Sp ${ }^{93}$ \\
\hline 72. !Bcl-3 $\rightarrow \mathrm{HDACl}$ & In the absence of $\mathrm{Bcl}-3, \mathrm{HDACl}$ binds to $\mathrm{p} 52$ dimers $^{36}$ \\
\hline
\end{tabular}

Notes: An exclamation mark denotes a logical NOT and a product sign (.) indicates an AND operation. 
to degradation of MDMX (equation 67), thus MDM2 stabilizes 553 by exerting an inhibitory effect on MDMX. ${ }^{35,37}$ Interestingly, MDM2 is able to ubiquitinylate p53 as well, which could also result in p53 degradation (equations 39 , $49,53,58$, and 65$).{ }^{38}$ Therefore, in terms of logical interaction hypergraphs, MDM2 is an ambivalent factor for p53 and Bcl-3/p52/p52.
Apart from ATR, breast cancer type 1 susceptibility protein (BRCA1) exerts also an inhibitory effect on the formation of the Bcl-3/p52/p52 complex through the ataxia telangiectasia mutated (ATM)-mediated phosphorylation of p53 (serine 15) in a BRCA1-dependent manner (equation 53). ${ }^{39-41}$ Thus, BRCA1 acts as an inhibitor of the Bcl-3/p52/p52 complex in a logical sense.

Table 2 The Boolean model species

\begin{tabular}{|c|c|c|c|}
\hline Species IDs & Full names & Species IDs & Full names \\
\hline AKT2(P) & & IL-I & \\
\hline $\operatorname{ATM}(\mathrm{P})$ & ATM(P)SI98I & IR & \\
\hline ATM(P)/NEMO(P) & ATM(P)SI98I/NEMO(P)S85 & $\mathrm{I} \kappa \mathrm{B} \alpha$ & \\
\hline ATM(P)/NEMO(Ub)/IKK $\beta$ & ATM(P)SI98I/NEMO(Ub)/IKK $\beta$ & $\mathrm{I} \kappa \mathrm{B} \beta$ & \\
\hline ATR/ATRIP & & MDM2 & \\
\hline BARDI/BRCAI(P) & BARD I/BRCA I (P) | 387(P)S I 423(P) I 524 & MDMX & \\
\hline Bcl-3 & & $\operatorname{MEK}(\mathrm{P})$ & MEK(P) (unspec. phosphoryl. site) \\
\hline $\mathrm{Bcl}-3 / \mathrm{p} 52 / \mathrm{p} 52$ & & MRN & Mrel I/Rad50/NbsI \\
\hline $\mathrm{Ca}^{2+}$ & & MRN(P) & Mre I I/Rad50/NbsI (P)S343 \\
\hline c-Abl(P) & c-Abl(P) (unspec. phosphoryl. site) & $\mathrm{NIK}(\mathrm{P})$ & \\
\hline Camptothecin & & Nuclear ATM(P)/NEMO(Ub) & Nuclear ATM(P)SI98I/NEMO(Ub) \\
\hline Caspase3 & & Nuclear NF-кB & \\
\hline Caspase7 & & Oxo8-Guanine & \\
\hline $\mathrm{Cdc} 25 \mathrm{C}(\mathrm{P})$ & $\mathrm{Cdc} 25 \mathrm{C}(\mathrm{P}) \mathrm{S} 216$ & p21 & \\
\hline $\mathrm{Cdc} 25 \mathrm{~A}$ & & P38 $8^{\text {MPPK }}(\mathrm{P})$ & (unspec. phosphoryl. site) \\
\hline Cdk2 & & p53(P)SI5 & \\
\hline Chkl(P) & ChkI(P)S3I7(P)S345 & p53(P)S20 & \\
\hline Chk2(P) & Chk2(P)T68 & $\mathrm{p} 90(\mathrm{P})$ & (unspec. phosphoryl. site) \\
\hline Cisplatin & & $\mathrm{PI} 3 \mathrm{~K}(\mathrm{P})$ & \\
\hline CK2 & & PIASy & \\
\hline Cyclin DI & & PIDD & \\
\hline Cytosolic ATM(P)/NEMO(Ub) & Cytosolic ATM(P)SI 98I/NEMO(Ub) & PIDD/RAIDD/caspase2 & \\
\hline Cytosolic NF-KB & & PIDD/RIPI/NEMO & \\
\hline Daunomycin & & PIDD/RIPI/NEMO(S) & $\begin{array}{l}\text { PIDD/RIPI/NEMO(SUMO-I) } \\
\text { K277(SUMO-I)K309 }\end{array}$ \\
\hline DNA_DSBs & & Pyrimidine_dimers & \\
\hline DNA-PK & & $\operatorname{RPA}(\mathrm{P})$ & RPA(P) (unspec. phosphoryl. site) \\
\hline Doxorubicin & & SN38 & \\
\hline $\mathrm{E} 2 \mathrm{~F}-\mathrm{I}(\mathrm{P})$ & E2F-I (P)S364 & Spl(P) & SpI (P) (unspec. phosphoryl. site) \\
\hline Egr-I & & Topoisomerasei & \\
\hline $\operatorname{ERK}(\mathrm{P})$ & ERK(P) (unspec. phosphoryl. site) & Topoisomeraseii & \\
\hline Gadd $45 \alpha$ & & UVA & \\
\hline Gadd $45 \beta$ & & UVB & \\
\hline $\mathrm{HDACl}$ & & UVC & \\
\hline IKK complex (P) & $\begin{array}{l}\text { IKK } \alpha / / \mathrm{IKK} \beta / \mathrm{NEMO}(\mathrm{P}) \\
\text { (unspec. phosphoryl. site) }\end{array}$ & VPI6 & \\
\hline IKK $\alpha(\mathrm{P})$ & IKK $\alpha(\mathrm{P}) \mathrm{T} 23$ & & \\
\hline
\end{tabular}

Abbreviations: P, phosphorylation; S, sumoylation (SUMO-I); Ub, ubiquitinylation. 
Table 3 Proteins of the output layer linked to apoptosis or cell survival

\begin{tabular}{ll}
\hline $\begin{array}{l}\text { Network components linked to apoptosis } \\
\text { and cell survival pathways }\end{array}$ & Explanations and references \\
\hline NF- KB (includes 52 dimers) & In most cases, NF- $\kappa B$ triggers antiapoptotic signaling ${ }^{16}$ \\
Caspases-3/7 & Caspases-3/7 promote apoptosis ${ }^{63}$ \\
p53(P)SI5 & p53(P)SI5 has proapoptotic functions ${ }^{45}$ \\
Caspase-2 & Caspase 2 promotes apoptosis upon activation in the PIDD/RAIDD/caspase2 complex ${ }^{9,46}$ \\
E2F-I(P)S364 & E2F-I(P)S364 promotes p53-dependent and p53-independent apotosis 89,94 \\
\hline
\end{tabular}

Notes: Activation of the proteins listed lead to either apoptotic or cell survival pathways.

Furthermore, our model predicted candidate kinases for MDMX, which are crucial for the degradation of MDMX. Previous studies have shown that the genotoxic stress-induced degradation of MDMX can be mediated not only by the wortmannin-sensitive kinase ATM but alternatively also by other wortmannin-sensitive kinases. ${ }^{42,35}$ Our network analysis revealed ATM, Chk2 (equation 66) and ATR (equation 60) as genotoxic stress-induced kinases, which could phosphorylate MDMX..$^{33-35,37,43}$ Since Chk2 itself is not wortmannin-sensitive, we predicted ATR as an additional kinase crucial for MDMX phosphorylationmediated degradation, whereby Chk2 is activated by ATR (equation 60). ${ }^{33,34}$

\section{Logical model of signal transduction induced by genotoxic stress}

In clinical practice, many cancers are treated with combined radio- and chemotherapy, which have a synergistic effect. ${ }^{44}$ Goal of this therapy is to induce apoptosis in treated tumor cells to eliminate the tumor. Using the logical model, we simulated the induction of the signal transduction in response to combined radio- and chemotherapy caused by ionizing radiation (equation 1) and VP16 (equation 4). This scenario mimics for instance treatment of lung cancer in patients. ${ }^{44}$

Ionizing radiation and VP16 induce activation of ATM (equations 7 to 9) and ATR (equations 54, 56) (Figure 3), which subsequently (ATM equation 53 and ATR equation 49) phosphorylate $\mathrm{p} 53$ at serine 15 leading to the activation of the expression of numerous proapoptotic genes.$^{45}$ Moreover, p53 phosphorylated at serine 15 leads to the degradation of Bcl-3, a binding partner and transcriptional coactivator of the NF- $\kappa B$ subunit $\mathrm{p} 52$. Upon degradation of Bcl-3, HDAC1 binds to the NF- $\kappa B$ subunit $\mathrm{p} 52$ leading to repression of the antiapoptotic p52 target genes (equations $40,41,72$ ). ${ }^{36}$

Simultaneously, DNA damage by DSBs can induce PIDD to form a complex with RIP-associated ICH-1/CED-3 homologous protein with a death domain (RAIDD) and caspase-2 (equation 51), constituting another pathway resulting in caspase-2 activation and apoptosis in epithelial cells and Jurkat T cells. ${ }^{8,10,46}$ However, two other reports suggest PIDD-independent caspase-2 activation and apoptosis following DNA damage in lymphocytes of mice and mouse embryo fibroblasts. ${ }^{47,48}$ Thus, the differences may be inherent to the cell types analyzed, as suggested by Manzl and colleagues. ${ }^{47}$ Further, DNA damage-induced regulation of the different PIDD isoforms is complex. DSBs induce upregulation of the PIDD isoform 3, and in addition proteolytic processing of PIDD varies among the isoforms of PIDD. ${ }^{8}$ Nevertheless, PIDD exerts a prominent role in DNA damage-induced apoptosis. An important role of PIDD in $\mathrm{NF}-\mathrm{\kappa B}$ activation is undoubtedly.

It is well known that the activation of NF- $\mathrm{KB}$ in response to radio- and chemotherapy plays a key role in the therapeutic resistance by activation of antiapoptotic genes. For this reason, it is eligible to inhibit the NF- $\kappa \mathrm{B}$ activation and enforce the expression of the proapoptotic genes ensuring the elimination of tumor cells. ${ }^{18}$ Therefore, in our in silico predictions, we focused on the identification of putative target structures suitable for abrogation of expression of NF- $\kappa B-$ regulated antiapoptotic genes.

By calculating minimal intervention sets with $C N A$, we identified PIDD as a target structure (Figure 4). Inhibition of the binding of PIDD to RIP1 will block activation of genotoxic stress-induced NF- $\mathrm{KB}$, and the desired induction of apoptosis will be achieved. PIDD exists in several isoforms. Isoforms 1 and 3 are involved in activation of caspase-2 leading to apoptosis (equation 51), isoform 2 is exclusively involved in activation of NF- $\mathrm{KB} .{ }^{8}$ Further, RIP1 or PIASy represent additional candidates, which are crucial for genotoxic stress-induced NF- $\mathrm{KB}$ activation. Herein, biochemical studies already identified PIDD $^{9}$ and RIP $1^{10}$ as mediators in activation of NF- $\mathrm{KB}$ by DNA DSBs. 


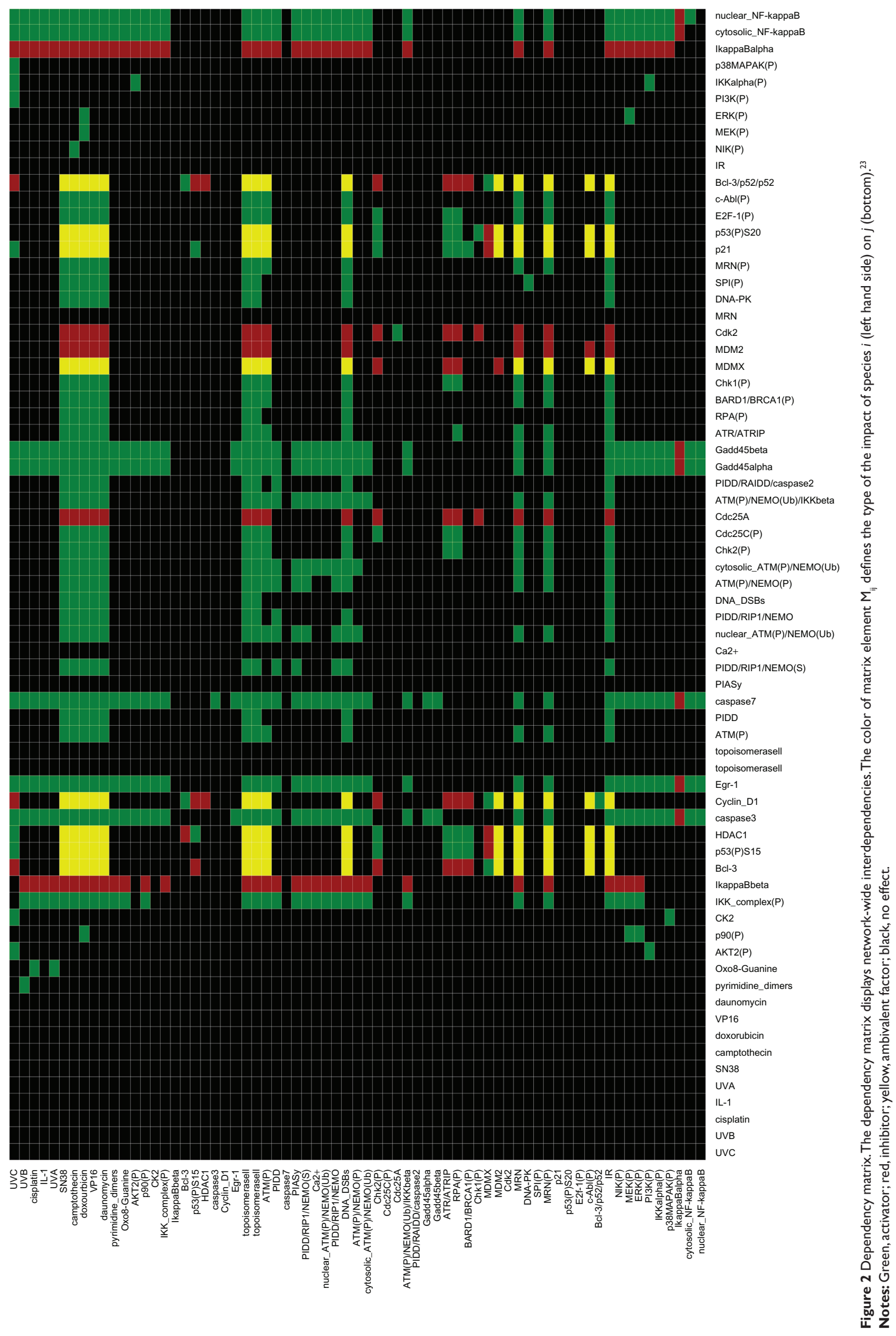




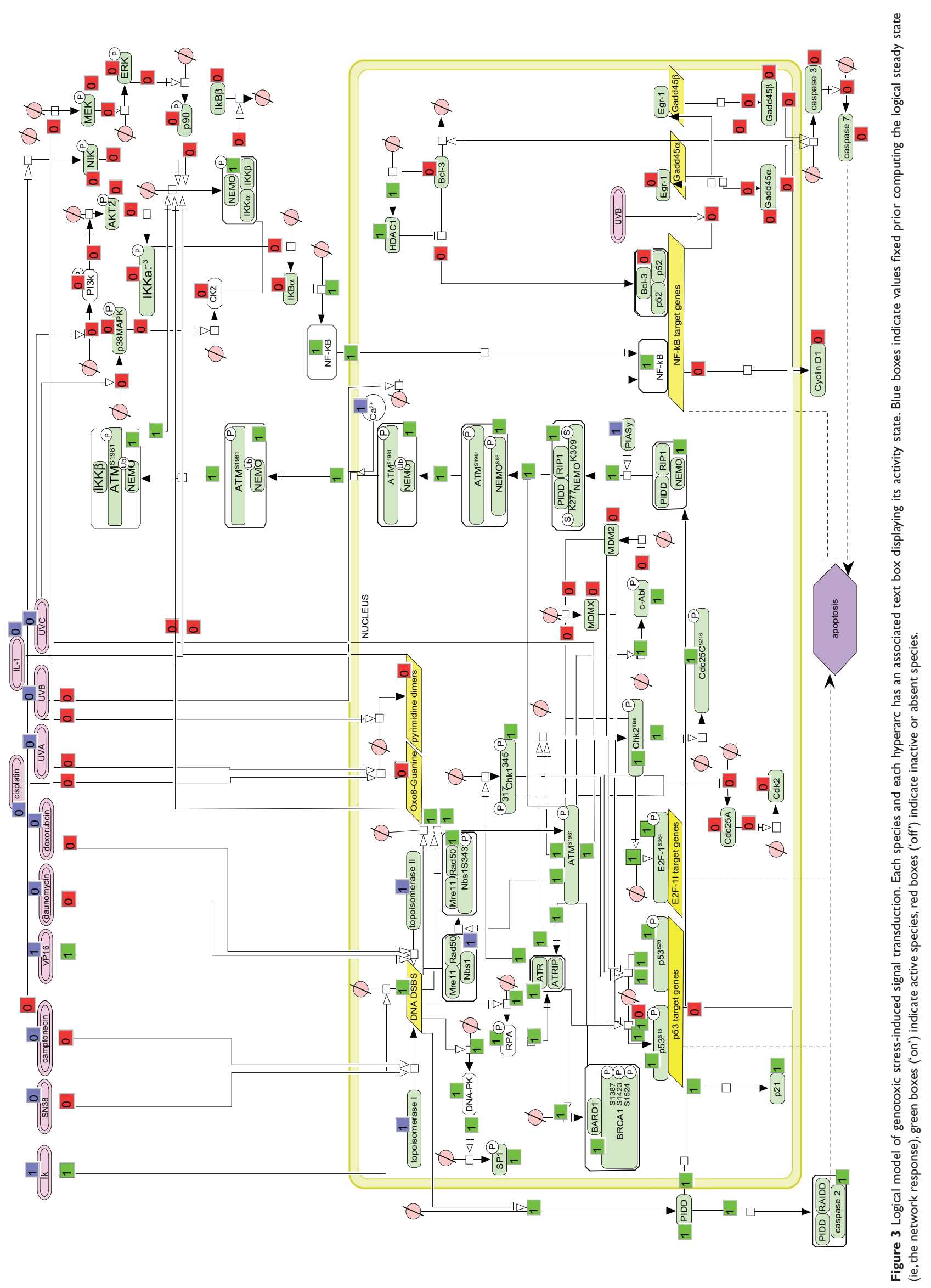




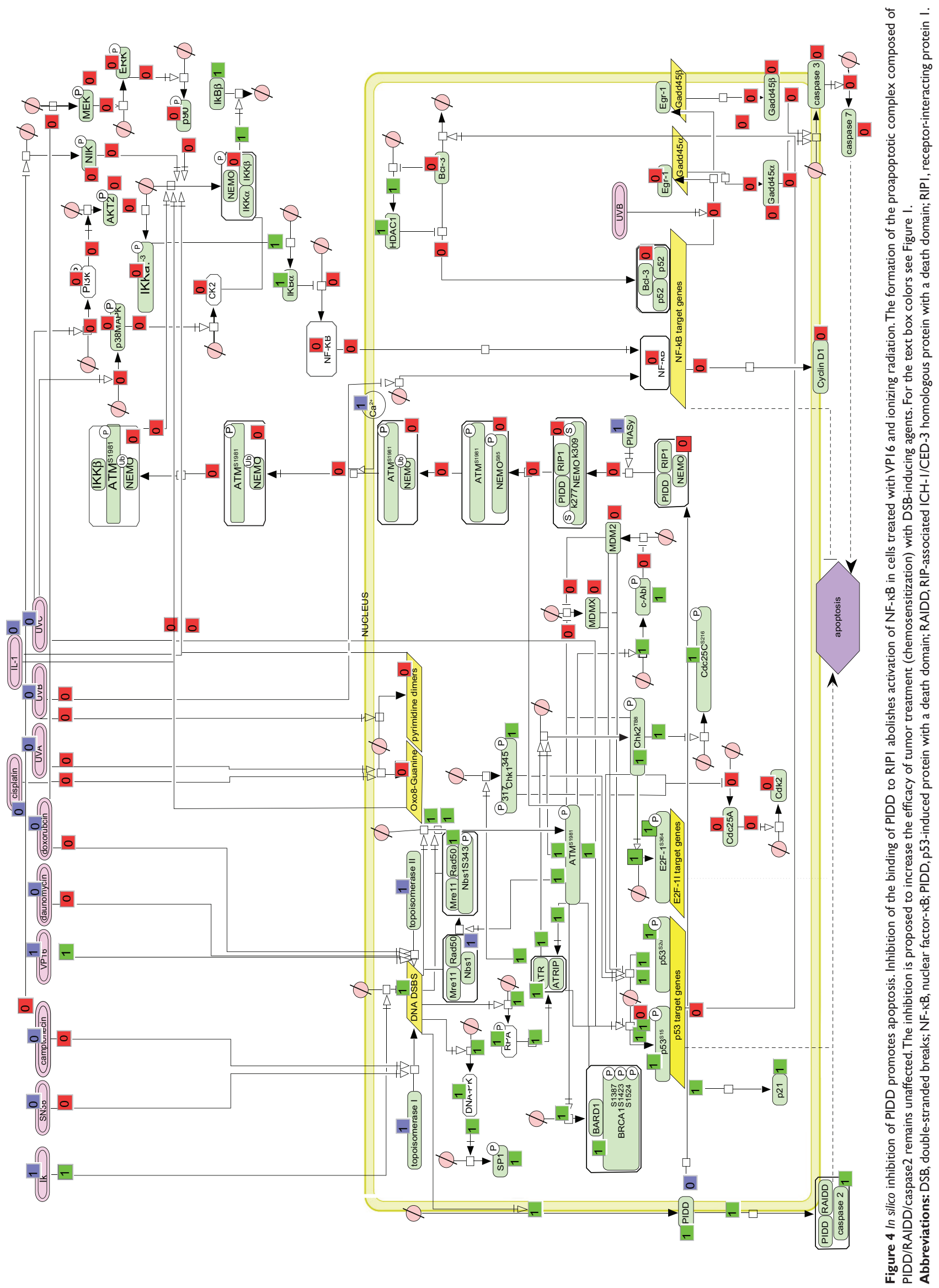


Additionally, we identified the MRN complex and ATM as putative target structures to prevent activation of $\mathrm{NF}-\kappa \mathrm{B}$. However, inhibition of MRN or ATM would also abrogate some of the pathways leading to activation of the proapoptotic proteins p53(P)S15 and E2F-1(P)S364. Therefore, the MRN complex and ATM might be less suitable therapeutic targets.

\section{Conclusions}

We presented a Boolean network model of signal transduction induced by genotoxic stress in human epithelial cells with a special emphasis on NF- $\kappa \mathrm{B}$ activation and apoptosis, which reveals the important functional interdependencies of protein activities. Recently, two Boolean network studies of apoptosis have been published. According to a study focusing on apoptosis induced by TNF and cell survival pathways induced by growth factors, ${ }^{49}$ the irreversibility of apoptosis mostly relies on positive feedback loops, while the stability of the cell survival states depends more on the presence of external prosurvival signals. Another study focused on apoptotic pathways induced by Fas ligand in hepatocytes. The authors integrated different apoptosis pathways and investigated several crosstalk possibilities. Four stable states of the network were identified, two states comprising cell survival and two states leading to apoptosis. ${ }^{50}$ Both reports focused on global network properties rather than on putative therapeutic applications. To our knowledge, until now, no model focusing on NF- $\kappa \mathrm{B}$ in genotoxic stress response has been published in such extent, in particular, with the focus on identification of target structures, which may potentiate radio- and chemotherapy. Furthermore, we identified the putative molecular targets PIDD, RIP1 and PIASy to abrogate the activation of NF- $\mathrm{KB}$ while leaving the apoptotic pathways unaffected, therefore resulting in apoptosis of tumor cells.

Overall, the model presented in our study identified target structures, which may increase the efficacy of radioand chemotherapy of tumors. Furthermore, our study provides for the first time a holistic model for both studying and understanding the signaling pathways in response to genotoxic stress, which may facilitate the understanding and interpretation of the large amount of published experimental data, hence indicating new targets for therapeutic strategies or drug discovery.

\section{Disclosures}

The authors declare that they have no competing interests. RP and RF built the logical model and RP performed the model analyses. MN, KS, SK and EDG participated in model design and analysis with valuable advice. RP and MN wrote the manuscript. MN coordinated the studies. All authors read and approved the final manuscript. The work was funded by the Federal Ministry of Education and Research (FORSYS, 0313922), and the Centre of Dynamical Systems (CDS) within the program networks of scientific excellence in Saxony-Anhalt (XD3639HP/0306) by grants to $\mathrm{MN}$.

\section{References}

1. Khanna KK, Jackson SP. DNA double-strand breaks: signalling, repair and the cancer connection. Nat Genet. 2001;27(3):247-254.

2. DeMarini DM. Genotoxicity of tobacco smoke and tobacco smoke condensate: a review. Mutat Res. 2004;567(2-3):447-474.

3. Shiloh Y. The ATM-mediated DNA-damage response: taking shape. Trends Biochem Sci. 2006;31(7):402-410.

4. Shimada M, Nakanishi M. DNA damage checkpoints and cancer. $J$ Mol Histol. 2006;37(5-7):253-260.

5. d'Adda di Fagagna F. Living on a break: cellular senescence as a DNA-damage response. Nat Rev Cancer. 2008;8(7):512-522.

6. Cann KL, Hicks GG. Regulation of the cellular DNA double-strand break response. Biochem Cell Biol. 2007;85(6):663-674.

7. Lisby M, Barlow JH, Burgess RC, Rothstein R. Choreography of the DNA damage response: spatiotemporal relationships among checkpoint and repair proteins. Cell. 2004;118(6):699-713.

8. Cuenin S, Tinel A, Janssens S, Tschopp J. p53-induced protein with a death domain (PIDD) isoforms differentially activate nuclear factorkappaB and caspase-2 in response to genotoxic stress. Oncogene. 2008;27(3):387-396.

9. Tinel A, Janssens S, Lippens S, et al. Autoproteolysis of PIDD marks the bifurcation between pro-death caspase-2 and pro-survival NF-kappaB pathway. EMBO J. 2007;26(11):197-208.

10. Janssens S, Tinel A, Lippens S, Tschopp J. PIDD Mediates NF- $\mathrm{KB}$ activation in response to DNA damage. Cell. 2005;123(6): 1079-1092.

11. Mabb AM, Wuerzberger-Davis SM, Miyamoto S. PIASy mediates NEMO sumoylation and NF-kappaB activation in response to genotoxic stress. Nat Cell Biol. 2006;8(9):986-993.

12. Wu ZH, Shi Y, Tibbetts RS, Miyamoto S. Molecular linkage between the kinase ATM and NF- $\mathrm{KB}$ signalling in response to genotoxic stimuli. Science. 2006;311(5764):1141-1146.

13. Huang TT, Wuerzberger-Davis SM, Wu ZH, Miyamoto S. Sequential modification of NEMO/IKKgamma by SUMO-1 and ubiquitin mediates NF-kappaB activation by genotoxic stress. Cell. 2003;115(5): 565-576.

14. Berchtold CM, Wu ZH, Huang TT, Miyamoto S. Calcium-dependent regulation of NEMO nuclear export in response to genotoxic stimuli. Mol Cell Biol. 2007;27(2):497-509.

15. Hayden MS, Gosh S. Shared principles in NF-kappaB signaling. Cell. 2008;132(3):344-362.

16. $\mathrm{Wu} \mathrm{ZH}$, Miyamoto $\mathrm{S}$. Many faces of NF- $\mathrm{\kappa B}$ signaling induced by genotoxic stress. J Mol Med. 2007;85(11):1187-1202.

17. Neumann M, Naumann M. Beyond I kappaBs: alternative regulation of NF-kappaB activity. FASEB J. 2007;21(11):2642-2654.

18. Orlowski RZ, Baldwin Jr AS. NF-kappaB as a therapeutic target in cancer. Trends Mol Med. 2002;8(8):385-389.

19. Sánchez L, Thieffry D. A logical analysis of the Drosophila gapgene system. J Theor Biol. 2001;211(2):115-1141. Erratum in: J Theor Biol. 2001;212(1):127.

20. Albert R, Othmer HG. The topology of the regulatory interactions predicts the expression pattern of the segment polarity genes in Drosophila melanogaster. J Theor Biol. 2003;223:1-18. 
21. Espinosa-Soto C, Padilla-Longoria P, Alvarez-Buylla ER. A gene regulatory network model for cell-fate determination during Arabidopsis thaliana flower development that is robust and recovers experimental gene expression profiles. Plant Cell. 2004;16(11):2923-2939.

22. Faure A, Naldi A, Chaouiya C, Thieffry D. Dynamical analysis of a generic Boolean model for the control of the mammalian cell cycle. Bioinformatics. 2002;22(14):e124-e131.

23. Klamt S, Saez-Rodriguez J, Lindquist JA, Simeonis L, Gilles ED. A methodology for the structural and functional analysis of signaling and regulatory networks. BMC Bioinformatics. 2006;7:56.

24. Klamt S, Saez-Rodriguez J, Gilles ED. Structural and functional analysis of cellular networks with CellNetAnalyzer. BMC Syst Biol. 2007;1:2.

25. Saez-Rodriguez J, Simeoni L, Lindquist JA, et al. A logical mode provides insights into $\mathrm{T}$ cell receptor signaling. PLoS Comput Biol. 2007;3(8):e163.

26. Franke R, Müller M, Wundrack N, et al. Host-pathogen systems biology: Logical modelling of hepatocyte growth factor and Helicobacter pylori induced c-Met signal transduction. BMC Syst Biol. 2008;2:4.

27. Schaefer CF, Anthony K, Krupa S, et al. PID: The Pathway Interaction Database. Nucleic Acids Res. 2009;(37)(Database issue): D674-D679.

28. Kanehisa M, Araki M, Goto, et al. KEGG for linking genomes to life and the environment. Nucleic Acids Res. 2008;(36)(Database issue): D480-D484

29. Sprenger J, Lynn Fink J, Karunaratne S, Hanson K, Hamilton NA, Teasdale RD. LOCATE: a mammalian protein subcellular localization database. Nucleic Acids Res. 2008;(36)(Database issue):D230-D233.

30. Funahashi A, Matsuoka Y, Jouraku A, Morohashi M, Kikuchi N, Kitano H. CellDesigner 3.5: A versatile modeling tool for biochemical networks. Proc IEEE. 2008;96(8):1254-1265.

31. Le Novère N, Hucka M, Mi H, et al. The Systems Biology Graphical Notation. Nat Biotechnol. 2008;27(8):735-741.

32. Lakin ND, Hann SP, Jackson SP. The ataxia-telangiectasia related protein ATR mediates DNA-dependent phosphorylation of p53. Oncogene. 1999;18(27):3989-3995.

33. Wang XQ, Redpath JL, Fan ST, Stanbridge EJ. ATR dependent activation of Chk2. J Cell Physiol. 2006;208(3):613-619.

34. Helt CE, Cliby WA, Keng PC, Bamabra RA, O’Reilly OA. Ataxia telangiectasia mutated (ATM) and ATM and Rad3-related protein exhibit selective target specificities in response to different forms of DNA damage. J Biol Chem. 2005;280(2):1186-1192.

35. Chen L, Gilkes DM, Pan Y, Lane WS, Chen J. ATM and Chk2-dependent phosphorylation of MDMX contribute to p53 activation after DNA damage. EMBO J. 2005;24:3411-3422.

36. Rocha S, Martin AM, Meek DW, Perkins ND. p53 represses cyclin D1 transcription through down regulation of $\mathrm{Bcl}-3$ and inducing increased association of the p52 NF-kappaB subunit with histone deacetylase 1 . Mol Cell Biol. 2003;23(13):4713-4727.

37. Pan Y, Chen J. MDM2 Promotes Ubiquitination and Degradation of MDMX. Mol Cell Biol. 2003;23(15):5113-5121.

38. Goldberg Z, Sionov RV, Berger M, et al. Tyrosine phosphorylation of $\mathrm{Mdm} 2$ by c-Abl: implications for p53 regulation. EMBO J. 2002;21(14):3715-3727.

39. Bakkenist CJ, Kastan MB. DNA damage activates ATM through intermolecular autophosphorylation and dimer dissociation. Nature. 2003;421(6922):499-506.

40. Fabbro M, Savage K, Hobson K, et al. BRCA1-BARD1 complexes are required for $\mathrm{p} 53^{\mathrm{Ser}-15}$ phosphorylation and $\mathrm{G}_{1} / \mathrm{S}$ arrest following ionizing radiation-induced DNA damage. J Biol Chem. 2004;279(30): 31251-31258.

41. Li W, Jian W, Xiaoping X, Yingfeng L, Tao X, Xiaoyan X. Enhanced radiation-mediated cell killing of human cervical cancer cells by small interference RNA silencing of ataxia telangiectasia-mutated protein. Int J Gynecol Cancer. 2006;16(4):1620-1630.

42. Meulmeester E, Pereg Y, Shiloh Y, Jochemsen AG. ATM-mediated phosphorylations inhibit Mdmx/Mdm2 stabilization by HAUSP in favor of p53 activation. Cell Cycle. 2005;4(9):1166-1170.
43. Pereg Y, Shkedy D, de Graaf P, et al. Phosphorylation of Hdmx mediates its Hdm2- and ATM-dependent degradation in response to DNA damage. Proc Natl Acad Sci U S A. 2005;102(14):5056-5061.

44. Rigas JR, Kelly K. Current treatment paradigms for locally advanced non-small cell lung cancer. J Thorac Oncol. 2007;2 Suppl 2:S77-S85.

45. Feki A, Jefford CE, Berardi P, et al. BARD1 induces apoptosis by catalysing phosphorylation of $\mathrm{p} 53$ by DNA-damage response kinase. Oncogene. 2005;24(23):3726-3736.

46. Tinel A, Tschopp J. The PIDDosome, a protein complex implicated in activation of caspase- 2 in response to genotoxic stress. Science. 2004;304(5672):843-846.

47. Manzl C, Krumschnabel G, Bock F, Sohm B, Labi V, Baumgartner F, et al. Caspase-2 activation in the absence of PIDDosome formation. J Cell Biol. 2009;185(2):291-303.

48. Kim IR, Murakami K, Chen NJ, et al. DNA damage- and stress-induced apoptosis occurs independently of PIDD. Apoptosis. 2009;14(9):1039-1049.

49. Mai Z, Liu H. Boolean network-based analysis of the apoptosis network: irreversible apoptosis and stable surviving. $J$ Theor Biol. 2009;259(4):760-769

50. Philippi N, Walter D, Schlatter R, et al. Modeling system states in liver cells: Survival, apoptosis and their modifications in response to viral infection. BMC Syst Biol. 2009;3(1):97.

51. Löbrich M, Rydberg B, Cooper PK. Repair of x-ray-induced DNA double-strand breaks in specific Not I restriction fragments in human fibroblasts: joining of correct and incorrect ends. Proc Natl Acad Sci US A. 1995;92(26):12050-12054.

52. Pommier Y. Topoisomerase I inhibitors: camptothecins and beyond. Nat Rev Cancer. 2006;6(10):789-802.

53. Baldwin EL, Osheroff N. Etoposide, topoisomerase II and cancer. Curr Med Chem Anticancer Agents. 2005;5(4):363-372.

54. Andoh T, Ishida R. Catalytic inhibitors of DNA topoisomerase II. Biochim Biophys Acta. 1998;1400(1-3):155-1571.

55. De Beer EL, Bottone AE, Voest EE. Doxorubicin and mechanical performance of cardiac trabeculae after acute and chronic treatment: a review. Eur. J. Pharmacol. 2001;415(1):1-11.

56. Dupré A, Boyer-Chatenet L, Gautier J. Two-step activation of ATM by DNA and the Mre11-Rad50-Nbs1 complex. Nat Struct Mol Biol. 2006; 13(5):451-457.

57. Robison JG, Bissler JJ, Dixon K. Replication protein A is required for etoposide-induced assembly of MRE11/RAD50/NBS1 complex repair foci. Cell Cycle. 2007;6(19):2408-2416. Epub 2007 Jul 20.

58. Lim DS, Kim ST, Xu B, et al. ATM phosphorylates p95/nbs1 in an S-phase checkpoint pathway. Nature. 2000;404(6778):613-617.

59. Li N, Karin M. Ionizing radiation and short wavelength UV activate NF-kB through two distinct mechanisms. Proc Natl Acad Sci U S A. 1998;95(22):13012-13017.

60. Habraken Y, Piret B, Piette J: S phase dependence and involvement of NF-kappaB activating kinase to NF-kappaB activation by camptothecin. Biochem Pharmacol. 2001;62(5):603-616.

61. Panta GR, Kaur S, Cavin LG, et al. ATM and the catalytic subunit of DNA-dependent protein kinase activate NF-kappaB through a common MEK/extracellular signal-regulated kinase/p90(rsk) signaling pathway in response to distinct forms of DNA damage. Mol Cell Biol. 2004;24(5):1823-1835.

62. Strozyk E, Pöppelmann B, Schwarz T, Kulms D. Differential effects of NF- $\kappa \mathrm{B}$ on apoptosis induced by DNA damage determines the final outcome. Oncogene. 2006;25(47):6239-6251.

63. Thyss R, Virolle V, Imbert V, Peyron JF, Aberdam D, Virolle T. NF-кB/ Egr-1/Gadd45 are sequentially activated upon UVB irradiation to mediate epidermal cell death. EMBO J. 2005;24(1):128-137.

64. Lewis DA, Spandau DF. UVB activation of NF- $\kappa$ B in normal human keratinocytes occurs via a unique mechanism. Arch Dermatol Res. 2007;299(2):93-101.

65. Yuan ZO, Feldman RI, Sun M, et al. Inhibition of JNK by cellular stressand tumor necrosis factor $\alpha$-induced AKT2 through activation of the NF $\kappa$ B pathway in human epithelial cells. J Biol Chem. 2002;277(33) 29973-29982. 
66. Huang TT, Feinberg SL, Suryanarayanan S, Miyamoto S. The zinc finger domain of NEMO is selectively required for NF-kappa B activation by UV radiation and topoisomerase inhibitors. Mol Cell Biol. 2002;22(16):5813-5825.

67. Fan C, Yang J, Engelhardt JF. Temporal pattern of NF- $\kappa B$ activation influences apoptotic cell fate in a stimuli-dependent fashion. J Cell Sci. 2002;115(Pt 24):4843-4853.

68. Bottero V, Busuttil V, Loubat A, et al. Activation of nuclear factor $\kappa B$ through the IKK complex by the topoisomerase poisons SN38 and doxorubicin: a brake to apoptosis in HeLa human carcinoma cells. Cancer Res. 2001;61(21):7785-7791.

69. DiDonato J, Mercurio F, Rosette C, et al. Mapping of the inducible IkappaB phosphorylation sites that signal its ubiquitination and degradation. Mol Cell Biol. 1996;16(4):1295-1304.

70. Kato T, Delhase M, Hoffmann A, Karin M. CK2 Is a C-terminal IkappaB kinase responsible for NF-kappaB activation during the UV response. Mol Cell. 2003;12(4):829-839.

71. Bender K, Göttlicher M, Whiteside S, Rahmsdorf HJ, Herrlich P. Sequential DNA damage-independent and -dependent activation of NF-kappaB by UV. EMBO J. 1998;17(17):5170-5181.

72. Brooks CL, Li M, Gu W. Mechanistic studies of MDM2-mediated ubiquitination in p53 regulation. $J$ Biol Chem. 2007;282(31): 22804-22815.

73. Huang RP, Fan Y, Boynton AL. UV irradiation upregulates Egr-1 expression at transcription level. J Cell Biochem. 1999;73(2):227-236.

74. Tanaka K, Hasegawa J, Asamitsu K, Okamoto T. Prevention of the ultraviolet $\mathrm{B}$-mediated skin photoaging by a nuclear factor kappaB inhibitor, parthenolide. J Pharmacol Exp Ther. 2005;315(2):624-630.

75. Zou L, Elledge SJ. Sensing DNA damage through ATRIP recognition of RPA-ssDNA complexes. Science. 2003;300(5625):1542-1548.

76. El-Deiry WS, Tokino T, Velculescu VE, et al. WAF1, a potential mediator of p53 tumor suppression. Cell. 1993;75(4):817-825.

77. Bean LJH, Stark GR. Phosphorylation of serines 15 and 37 is necessary for efficient accumulation of $\mathrm{p} 53$ following irradiation with UV. Oncogene. 2001;20(9):1076-1084.

78. Han Z, Wei W, Dunaway S, et al. Role of $\mathrm{p} 21$ in apoptosis and senescence of human colon cancer cells treated with camptothecin. J Biol Chem. 2002;277(19):17154-17160.

79. Cortez D, Ang Y, Quin J, Elledge SJ. Requirement of ATM-dependent phosphorylation of Brcal in the DNA damage response to doublestrand breaks. Science. 1999;286(5442):1162-1166.

80. Gatei M, Scott SP, Filippovitch I, et al. Role for ATM in DNA damageinduced phosphorylation of BRCA1. Cancer Res. 2000;60(12): 3299-3304.
81. Adams KE, Medhurst AL, Dart DA, Lakin ND. Recruitment of ATR to sites of ionising radiation-induced DNA damage requires ATM and components of the MRN protein complex. Oncogene. 2006;25(28): 3894-3904.

82. Zhao H, Piwnica-Worms H. ATR-mediated checkpoint pathways regulate phosphorylation and activation of human Chk1. Mol Cell Biol. 2001;21(13):4129-4139.

83. Shieh SY, Ahn J, Tamai K, et al. The human homologs of checkpoint kinases Chk1 and Cds1 (Chk2) phosphorylate p53 at multiple DNA damage-inducible sites. Genes Dev. 2000;14(3):289-300. Erratum in: Genes Dev. 2000;14(6):750.

84. Melchionna R, Chen XB, Blasiani A, McGowan CH. Threonine 68 is required for radiation-induced phosphorylation and activation of Cds1. Nat Cell Biol. 2000;2(10):762-765.

85. Falck J, Mailand N, Syljuasen RG, Bartek J, Lukas J. The ATM-Chk2Cdc25A checkpoint pathway guards against radioresistant DNA synthesis. Nature. 2001;410(6830):842-847.

86. Jin J, Ang XL, Ye X, Livingstone M, Harper JW. Differential roles for checkpoint kinases in DNA damage-dependent degradation of the Cdc25A protein phosphatase. J Biol Chem. 2008;283(28): 19322-19328.

87. Blomberg I, Hoffmann I. Ectopic expression of Cdc25A accelerates the G1/S transition and leads to premature activation of cyclin E- and cyclin A-dependent kinases. Mol Cell Biol. 1999;19(9):6183-6194.

88. Matsuoka S, Huang M, Elledge SJ. Linkage of ATM to cell cycle regulation by the Chk2 protein linase. Science. 1998;282(5395): 1893-1897.

89. Stevens C, Smith L, La Thangue NB. Chk2 activates E2F-1 in response to DNA damage. Nat Cell Biol. 2003;5(5):401-409.

90. Pabla N, Huang S, Mi QS, Daniel R, Dong Z. ATR-Chk2 signaling in p53 activation and DNA damage response during cisplatin-induced apoptosis. J Biol Chem. 2008;283(10):6572-6583.

91. Baskaran R, Wood LD, Whitaker LL, et al. Ataxia telangiectasia mutant protein activates $\mathrm{c}-\mathrm{Abl}$ tyrosine kinase in response to ionizing radiation. Nature. 1997;387(6632):516-519.

92. Foray N, Marot D, Randrianarison V, et al. Constitutive association of BRCA1 and c-Abl and its ATM-dependent disruption after irradiation. 2002. Mol Cell Biol. 22(12):4020-4032.

93. Niina I, Uchiumi T, Izumi H, et al. DNA topoisomerase inhibitor, etoposide, enhances GC-box-dependent promotor activity via $\mathrm{Sp} 1$ phosphorylation. Cancer Sci. 2007;98(6):858-863.

94. Dong YB, Yang HL, McMasters KM. E2F-1 overexpression sensitizes colorectal cancer cells to camptothecin. Cancer Gene Ther. 2003; 10(3):168-178.

\section{Publish your work in this journal}

Advances and Applications in Bioinformatics and Chemistry is an international, peer-reviewed open-access journal that publishes articles in the following fields: Computational biomodelling; Bioinformatics; Computational genomics; Molecular modelling; Protein structure modelling and structural genomics; Systems Biology; Computational

\section{Dovepress}

Biochemistry; Computational Biophysics; Chemoinformatics and Drug Design; In silico ADME/Tox prediction. The manuscript management system is completely online and includes a very quick and fair peerreview system, which is all easy to use. Visit http://www.dovepress.com/ testimonials.php to read real quotes from published authors. 